\title{
Pan-Pacific Enterprises: Strategic Decision-Making In Action
}

Dallas Brozik, (E-mail: brozik@marshall.edu), Marshall University

Alina Zapalska, (E-mail: zapalska@marshall.edu), Marshall University

Christopher Cassidy, (E-mail: cassidyc@marshall.edu), Marshall University

\begin{abstract}
Pan-Pacific Enterprises creates an environment in which individual teams must make strategic decisions based on conflicting goals. The game lasts a single class period but does require outside preparation by the students. Several different groups are given the planning responsibility for a certain aspect of firm operations, yet the optimal solutions for each goal are incompatible. It then becomes the responsibility of the group to resolve these differences and develop a unified plan.
\end{abstract}

\section{INTRODUCTION}

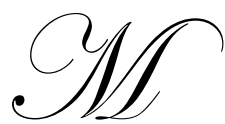

ost games and simulations are designed to teach skills or illustrate specific market concepts. Competition and cooperation can be demonstrated through interactive exercises, and economic concepts can be given form. While all of these activities are valuable, they typically have a definite result or target lesson. Life is not so accommodating; there is simultaneity in action and an incompatibility of goals in virtually every business activity. If events can be predicted, a computer can be programmed to do the work, but a computer program is not a manager. Management is about handling the conflicts that arise when people of good intention work together but not in harmony. The purpose of the Pan-Pacific Enterprises simulation is to create an environment in which the goal is known but unattainable. This provides students with a real test of managerial ability.

\section{PEDAGOGICAL DESIGN}

Pan-Pacific Enterprises is designed to be a capstone experience. Students need to have a reasonable set of business skills to get the most out of the simulation. The simulation is set in a rich environment that allows students to do their best with their various skills. But the environment is deceptive, and students tend to focus on sub-goals and lose track of the overall goal of the firm. As a group, the students then face the task of reconciling quite different solutions to create a unified plan.

This simulation creates a multinational firm with widespread interests and responsibilities. As within most businesses, PanPac Enterprises has a number of different responsibility centers. Different functional groups are tasked with developing their own portion of the annual strategic plan in accordance with their individual goals, but the goals are not perfectly compatible between groups. For instance, it may save money to have production facilities in countries with low wage rates, but it will also be more expensive to ship those finished goods to the final markets. The groups must then devise a unified strategy to present to the Chief Executive Officer (the instructor). Sufficient information is provided for the different groups to formulate their plans, but this information is tailored to provide no common solution.

The real thrust of the simulation is for the groups to find common ground and develop a single plan. This ultimately requires cooperation and negotiation rather than mere calculation. There are no wrong or right answers, since the goal of the simulation is to allow the students to experience a process. Students have the opportunity to learn that numbers are not answers and that answers may not be easy. 
PanPac is designed as a single period exercise. While there are many good strategy games and simulations that cover many aspects of management, these exercises can cover many periods and require tight scheduling. PanPac only requires that students be formed into teams and given their tasks prior to the period of play. The concise nature of the simulation provides the instructor with flexibility in scheduling.

\section{PLAYING PANPAC}

PanPac is designed for classes of 20 to 40 students. There are several functional areas, and each should have a team of three to five members. While some two-member teams are acceptable, it is suggested that in classes of fewer than 20 students that the number of groups be limited so that there are at least three students per team. This can be done simply by eliminating one or more of the functional groups. Larger classes can be accommodated by creating additional functional groups and developing goals that are reasonable but incompatible with at least one other group.

The Briefing Book (Appendix A) is distributed to each team prior to the simulation. There is a significant amount of information in the Briefing Book that is relevant to the decision process, and it is not possible to assimilate it during a single period of play. Students need the time outside of class to formulate their own optimal solutions to the planning problem. The time spent in class should be time spent discovering the differences in the "optimal" solutions and finding a middle ground. Students should not be informed of this, however. They need to discover the nature of their disagreements and devise their own techniques for reaching consensus.

The goals for each functional group are summarized in Appendix B. A copy of each group's individual goal should be provided to it on a separate sheet with a copy of the Briefing Book. The summary of all goals should be withheld from the class until after the exercise and should be used to illustrate the inherent conflicts due to the stated goals for each functional group. Whether or not the groups share this information outside of class is up to the instructor. It is suggested that no guidance be given on this point in order to discover the degree to which students will collaborate.

The Briefing Book presents all the information each functional group requires to develop its own solution. In fact, there is more information there than any individual group needs. There is sufficient information for some groups to construct linear programming solutions to find individual optimal strategies. Finding an optimal solution can make a group confident that it knows "the answer". The surprise comes when different groups present optimal solutions that are incompatible. Students who are highly competent in numeric skills may not initially recognize that a problem can have multiple incompatible solutions. They also may take "ownership" and try to protect their solution.

Once the play begins, the students are simply tasked with presenting a single strategic plan. The use of multiple groups allows the confusion level to be quite high. Those groups that have worked hard to develop their own plans will fight to make their vision part of the final product. The process of negotiation will begin with a discovery phase where each group finds out what the other groups want to do. The information flow may be streamlined or chaotic, depending on the abilities of the students. It is quite likely that the initial information exchange will be on a one-to-one basis where members of each group seek out members of other groups.

When it finally becomes apparent that the various proposed solutions are in fact at odds with each other, there will be a period when the class attempts to figure out how to handle the problem. This is the time when the dominant personalities will take charge. If there is only one dominant individual, he or she will assume control of the situation. When multiple dominant personalities are present, there will be a negotiation for control or the formation of a formal or informal "committee" to direct the process. Students may ask the instructor how to make all this work, but the instructor must not give any suggestions. This is the point of the simulation.

The development of the final plan can last throughout the entire period or longer, but it is necessary for the instructor to reserve the last ten minutes or so for discussion. Even if a final recommendation is not ready, the simulation must be stopped. During the discussion period, the focus should be on the group dynamics necessary to reach an agreement in the presence of differing opinion. Students must be made aware that working from common information cannot guarantee harmony if goals are not compatible or stated completely. Some time should also be 
spent on recognizing that this is actually the type of situation that exists in many firms. This time is most profitably spent considering nature of interpersonal interaction rather than information processing skills.

\section{CONCLUSION}

Pan-Pacific Enterprises is a simulation designed to provide students with the opportunity to explore the realities of strategic planning in a complex environment. There are no optimal solutions to be revealed through mathematical programming or normative models. People who are working for the common good can and will have different visions of the correct plan of action, but the real trick is in finding the common ground that leads to a practical solution. Pan-Pac gives students a chance to experience the practical difficulties of management and strategic planning and identify the limitations of quantitative modeling.

APPENDIX A

Pan-Pacific Enterprises Briefing Book

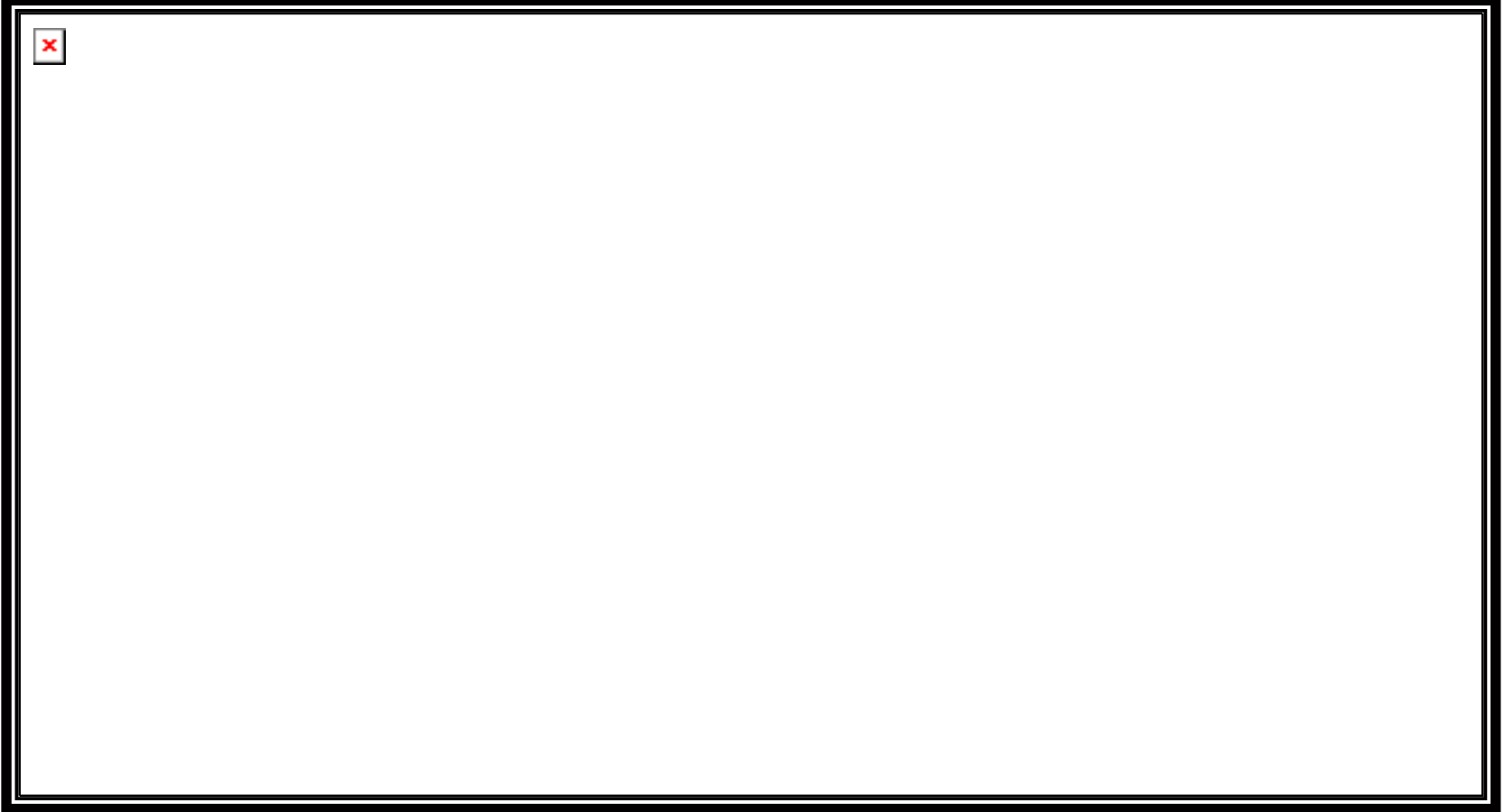

PAN-PACIFIC ENTERPRISES

\section{Company Overview}

Pan-Pacific Enterprises is a multinational firm with production, distribution, and marketing activities in North America and the Pacific Basin. The stated goal of the firm is to maximize the returns to its shareholders by developing and marketing superior products that meet the needs of the consumers while providing a challenging and rewarding environment for employees. PanPac is integrated through all aspects of the production process, from raw materials, through intermediate products, to final consumer goods. The firm is run by an aggressive management team that continually seeks new business opportunities. 


\section{Present Situation}

The PanPac management team is about to develop next year's strategic plan. This plan will encompass all of the firm's activities, but as a practical matter it will primarily focus on expansion projects. The existing plants and marketing efforts are all in satisfactory condition and are expected to remain so for the next several years. Due to the nature of the markets in which PanPac operates, new activities will not affect existing operations, so it will not be necessary to worry about cannibalization for this planning period.

\section{Financial Environment}

PanPac's size makes it possible for the firm to deal with financial institutions around the world. The company's stock is widely held, and all previous bond and stock issues have been well received by investors. The firm's performance has been such that there should be no difficulty in selling the securities necessary to finance any new projects. PanPac is also on good terms with major international banks and has the ability to borrow short-term funds as needed. The new strategic plan will therefore be able to focus on the projects themselves rather than be concerned with sources of external funding.

\section{Market Areas}

PanPac has identified several global areas that function as distinct product markets. PanPac operates in three of these areas: North America, Asia, and Oceania. The map on the cover page of this Briefing Book shows the extent of each of these market areas.

\section{Production Process}

PanPac's production processes fall into three distinct categories.

\section{Raw Materials (RM)}

This aspect of production involves mining ores and minerals, drilling for petroleum based products, and harvesting renewable resources like timber.

\section{Intermediate Goods (IG)}

In this part of the production process, the raw materials are converted to commodity stock like metal ingot, plastic, and lumber.

\section{Consumer Products (CP)}

Intermediate goods are transformed into finished goods and sold to the ultimate consumers.

Based on the mix of products offered, PanPac has found that it takes four units of raw materials to create two units of intermediate goods that can then be made into one unit of consumer products. This relationship is known as the 4/2/1 mix and is illustrated below: 


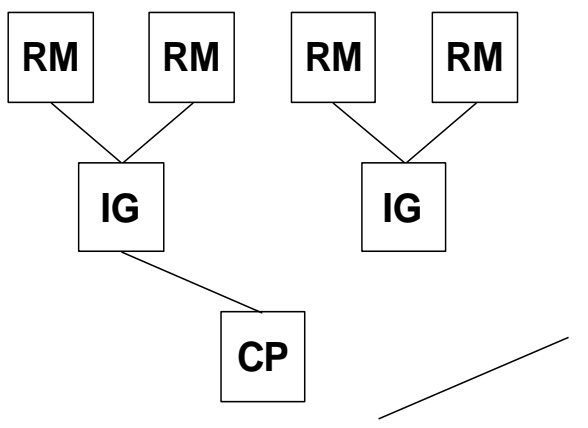

It is expected that this 4/2/1relationship will remain the same for any new projects undertaken. Since PanPac's raw materials and intermediate goods are similar to those offered by other firms, such products are considered substitutes. In practice this means the factories that manufacture intermediate goods are not required to purchase raw materials from other PanPac subsidiaries, nor are these factories required to sell their products to those PanPac subsidiaries that manufacture consumer products. Each step of the production process can be considered to be independent from every other step.

Any division of PanPac can purchase any of its inputs or sell any of its output to any other company. This also means that the transfer prices used when PanPac's units do sell to each other are the market prices of the goods. There are no internal subsidies created by inappropriate transfer prices. Due to the nature of the various markets, any input can be purchased in sufficient quantity at market prices, and all outputs can be sold at market prices. Products purchased from or sold to outside organizations, whether inside or outside the geographic area, are charged the transportation and distribution costs associated with inter-area transfers of goods produced with PanPac.

PanPac has two production policies relevant to this planning process. PanPac does not want to become dependent on secondary markets for its products. To this end, the firm will only manufacture enough product to meet its projected demand in all product categories. If it is more economical to sell goods to outside firms in one market and buy the same goods from outside firms in another market, that is acceptable as long as the total amount manufactured equals the total amount sold. Corporate policy also limits the amount of merchandise that can be purchased from outside organizations to no more than $10 \%$ of the total unit volume of PanPac sales in each respective product category. While there is no restriction concerning how much product can be sold to outside organizations, this restriction on outside purchases and the requirement for balanced production effectively means that no more than $10 \%$ of PanPac products will be sold to outside firms.

To illustrate these two restrictions, assume that PanPac projects a total demand of 10,000 Consumer Products across its three geographic market segments. The firm will then produce 10,000 Consumer Products at its various manufacturing facilities. Further assume that 5,000 of these Consumer Goods were destined for the Asian market. Those 5,000 goods could be manufactured in Asia and used locally or manufactured in North America or Oceania and shipped to Asia. A maximum of 1,000 units could be purchased from outside suppliers in Asia. No more than 1,000 units of Consumer Goods can be purchased from or sold to outside firms in order to keep within the 10\% guideline. For each unit purchased from an outside supplier in Asia, another unit manufactured in North America or Oceania would be sold to an outside firm in order to keep production and sales in balance according to corporate policy.

\section{ACCOUNTING PROCEDURES AND INFORMATION}

Due to its size and international presence, PanPac deals in many different currencies. In order to simplify internal communications, the accounting department reports all monetary values in an Artificial Currency Unit (ACU) instead of dollars, yen, or yuan. The ACU is a weighted average of all currencies used by PanPac, adjusted for the inflation rates of the various currencies. This procedure has been in place for several years and has proven to be satisfactory for planning purposes; it will be used for the current planning process. Existing factories are meeting the current market demand, but they are operating at full capacity. It will be necessary to build new factories in order to supply any new demand.

The information on the following pages describes PanPac, its markets, and future opportunities. The information is presented in no particular order. Not all of the information may be relevant to all possible decisions. 
This information is based on the best research and analysis available and may be considered accurate for planning purposes.

\begin{tabular}{|l|c|c|c|}
\hline \multicolumn{4}{|c|}{ Current Market Demand (Units) } \\
\hline & Raw Materials & Intermediate Goods & Consumer Products \\
\hline North America & $20,000,000$ & $12,000,000$ & $7,000,000$ \\
\hline Asia & $15,000,000$ & $8,000,000$ & $3,500,000$ \\
\hline Oceania & $15,000,000$ & $5,000,000$ & $2,000,000$ \\
\hline
\end{tabular}

\begin{tabular}{|l|c|c|c|}
\hline \multicolumn{3}{|c|}{ Projected Average Annual Real Growth Rate In Demand } \\
\hline & Raw Materials & Intermediate Goods & Consumer Products \\
\hline North America & $5 \%$ & $10 \%$ & $10 \%$ \\
\hline Asia & $15 \%$ & $9 \%$ & $16 \%$ \\
\hline Oceania & $10 \%$ & $7 \%$ & $9 \%$ \\
\hline
\end{tabular}

\begin{tabular}{|l|c|c|c|}
\hline \multicolumn{4}{|c|}{ Hours Of Labor/Unit Of Output } \\
\hline & Raw Materials & Intermediate Goods & Consumer Products \\
\hline North America & 2 & 3 & 2 \\
\hline Asia & 4 & 4 & 6 \\
\hline Oceania & 3 & 3 & 3 \\
\hline
\end{tabular}

\begin{tabular}{|l|c|c|c|}
\hline \multicolumn{4}{|c|}{ Current Hourly Labor Costs (ACU) } \\
\hline & Raw Materials & Intermediate Goods & Consumer Products \\
\hline North America & 2 & 4 & 5 \\
\hline Asia & 0.8 & 1 & 3 \\
\hline Oceania & 1.2 & 2.5 & 4 \\
\hline
\end{tabular}

\begin{tabular}{|l|c|c|c|}
\hline \multicolumn{3}{|c|}{ Projected Average Annual Real Growth Rate In Labor Costs } \\
\hline & Raw Materials & Intermediate Goods & Consumer Products \\
\hline North America & $4 \%$ & $6 \%$ & $5 \%$ \\
\hline Asia & $10 \%$ & $9 \%$ & $12 \%$ \\
\hline Oceania & $5 \%$ & $8 \%$ & $8 \%$ \\
\hline
\end{tabular}

\begin{tabular}{|c|c|c|c|}
\hline \multicolumn{4}{|c|}{ Production Costs Per Unit Of Output (ACU) } \\
\hline & Raw Materials & Intermediate Goods & Consumer Products \\
\hline North America & 2.0 & 3.0 & 5.0 \\
\hline Asia & 1.2 & 2.0 & 3.0 \\
\hline Oceania & 1.5 & 2.6 & 4.0 \\
\hline
\end{tabular}




\begin{tabular}{|l|l|}
\hline \multicolumn{2}{|c|}{ Transportation Costs } \\
\hline $\begin{array}{l}\text { Transportation and distribution costs within a geographic market area (north } \\
\text { America, Asia, Oceania) }\end{array}$ & $\begin{array}{l}\text { Raw Materials: 1 ACU/unit } \\
\text { Intermediate Goods: 1 ACU/unit } \\
\text { Consumer Products: 2 ACU/unit }\end{array}$ \\
\hline $\begin{array}{l}\text { Transportation and distribution costs to any other geographic market area (Asia to } \\
\text { North America, Asia to Oceania, North America to Asia, North America to } \\
\begin{array}{l}\text { Oceania, Oceania to North America, Oceania to Asia) and all goods purchased } \\
\text { from or sold to outside organizations in any market area }\end{array}\end{array}$ & $\begin{array}{l}\text { Intermediate Goods: 2 ACU/unit } \\
\text { Consumer Products: 2 ACU/unit }\end{array}$ \\
\hline
\end{tabular}

\begin{tabular}{|l|c|c|c|}
\hline \multicolumn{4}{|c|}{ New Factory Production Capacity (Units) } \\
\hline & Raw Materials & Intermediate Goods & Consumer Products \\
\hline North America & 300,000 & 250,000 & 400,000 \\
\hline Asia & 250,000 & 300,000 & 300,000 \\
\hline Oceania & 300,000 & 250,000 & 250,000 \\
\hline
\end{tabular}

Note: Though the factories for each product category make a standard product that can be sold anywhere, differences in local environmental regulations and infrastructure result in different levels of production.

\begin{tabular}{|l|c|c|c|}
\hline \multicolumn{4}{|c|}{ Market Selling Price Per Unit (ACU) } \\
\hline & Raw Materials & Intermediate Goods & Consumer Products \\
\hline North America & 7.00 & 37.00 & 110.00 \\
\hline Asia & 5.50 & 20.00 & 80.00 \\
\hline Oceania & 6.00 & 27.00 & 90.00 \\
\hline
\end{tabular}

\begin{tabular}{|l|c|c|c|}
\hline \multicolumn{4}{|c|}{ Profit Per Unit Within Geographic Area (ACU) } \\
\hline & Raw Materials & Intermediate Goods & Consumer Products \\
\hline North America & 0.840 & 7.297 & 20.539 \\
\hline Asia & 0.780 & 2.042 & 15.358 \\
\hline Oceania & 0.720 & 4.914 & 21.476 \\
\hline
\end{tabular}

\section{PLANNING PROCESS}

Since a strategic plan must consider all aspects of an organization's operations, PanPac is organized into several functional areas. The functional area groups are as follows:

\section{Construction Services}

1. Facilities Management

2. International Relations

3. Labor Management

4. Market Planning

5. Production Management

6. Shareholder Relations

7. Transportation Management 
Each functional area group is responsible for developing a strategic plan that addresses its specific concerns. Information about the specific concerns of each functional area will be provided separately to each group. The plan developed by each group should specify the following information:

1. The types and locations of factories to be built.

2. The source of each factory's inputs, if applicable (internal or external).

3. The final market of each factory's output (internal or external).

During the development of the strategic plan, each group is free to communicate with any other group.

Once each group develops its individual recommendations, all groups must meet together to work out a single combined strategic plan. Each group will be held responsible to see that its individual concerns are properly addressed in the overall strategic plan.

Once a final strategic plan has been developed, the groups will appoint a spokesperson to present the final strategic plan to the Chief Executive Officer (the instructor). After this plan is presented, the CEO is free to question any and all group members regarding the final plan and how it addresses the concerns of their specific functional areas.

\section{APPENDIX B}

\section{Summary Of Goals}

\section{Construction Services Group}

The Construction Services Group is responsible for controlling construction costs throughout the entire organization. The goal of this group is to achieve the lowest overall construction costs for any new facilities. The cost of building a factory in any given location is roughly the same in all market areas due to local laws and the accessibility of proper building materials and equipment. For strategic planning purposes, this means new factories with the highest production capacities should be built in order to minimize construction costs.

\section{Facilities Management Group}

The Facilities Management Group is responsible for identifying the proper location for any new facilities throughout the entire organization. Experience has shown that it is easier to build future facilities in areas where PanPac factories already exist. Future profitability will depend on whether future markets can be established in areas with low production and labor costs. For strategic planning purposes, this means identifying those locations where new factories should be built that will have the lowest growth rates in labor and production costs.

\section{International Relations Group}

The International Relations Group is tasked with maintaining PanPac's political position in the global market. There is much concern that industrialized countries are exploiting developing countries for their cheap labor and more relaxed environmental standards. The goal of the group is to assure that the Production costs/Labor costs/product Demand mix (referred to as the P/L/D mix) in each market area roughly matches the demand for products (weighted by volume) in those areas.

For example, if the North American market area demand for Consumer Products is 5\% of the total output of the firm (weighted by volume), then $5 \%$ of the firm's total production costs and $5 \%$ of the firm's total labor costs should be from North American market area Consumer Products.

For strategic planning purposes, this means identifying those locations where new factories should be built that will achieve an overall balanced P/L/D ratio in each market area. 


\section{Labor Management Group}

The Labor Management Group is responsible for controlling labor costs throughout the entire organization. The goal of this group is to achieve the lowest overall labor costs for the entire firm by identifying and employing the lowest cost labor resources in all of Pan-Pac's market areas. For strategic planning purposes, this means identifying those locations where new factories should be built that will have cheapest possible labor sources.

\section{Market Planning Group}

The Market Planning Group is responsible for identifying the proper location for any new facilities throughout the entire organization. Experience has shown that it is easier to establish future markets in areas where Pan-Pac factories already exist. Future profitability will depend on whether future markets can be established in areas with high potential growth. For strategic planning purposes, this means identifying those locations where new factories should be built that will have the highest growth rate in demand.

\section{Production Management Group}

The Production Management Group is responsible for controlling production costs throughout the entire organization. The goal of this group is to achieve the lowest overall production costs for the entire firm by identifying and employing the lowest production costs in all of Pan-Pac's market areas. For strategic planning purposes, this means identifying those locations where new factories should be built that will have cheapest possible production costs.

\section{Shareholder Relations Group}

The Shareholder Relations Group is responsible for maintaining good relationships with Pan-Pac's shareholders. Since most of the shareholders are primarily concerned with the short-term profitability of the firm, the goal of this group is to maximize the next period's profits. For strategic planning purposes, this means identifying those locations where new factories should be built that will achieve the highest profits for the firm.

\section{Transportation Management Group}

The Transportation Management Group is responsible for minimizing transportation costs throughout the entire organization. The goal of this group is to achieve the lowest overall transportation costs for the entire firm. For strategic planning purposes, this means identifying those locations where new factories should be built that will have cheapest possible transportation costs when shipping goods either within the market area or to other market areas. 
NOTES 